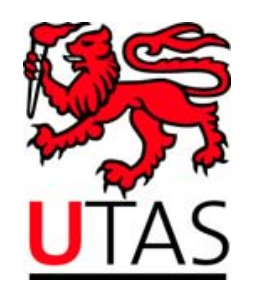

SCHOOL OF ECONOMICS AND FINANCE

Discussion Paper 2012-01

\title{
On the Correspondence Between Data Revision and Trend-Cycle Decomposition
}

Mardi Dungey, Jan P.A.M. Jacobs

and

Jing Tian

ISSN 1443-8593

ISBN 978-1-86295-656-8 


\title{
On the correspondence between data revision and trend-cycle decomposition
}

\author{
Mardi Dungey \\ University of Tasmania, CFAP, University of Cambridge, CAMA \\ Jan P.A.M. Jacobs
}

Faculty of Economics and Business, University of Groningen, CAMA and CIRANO

\author{
Jing Tian* \\ University of Tasmania \\ Simon van Norden \\ HEC Montréal, CAMA, CIRANO and CIREQ
}

March 2012

\begin{abstract}
This paper places the data revision model of Jacobs and van Norden (2011) within a class of trend-cycle decompositions relating directly to the Beveridge-Nelson decomposition. In both these approaches identifying restrictions on the covariance matrix under simple and realistic conditions may produce a smoothed estimate of the underlying series which is more volatile than the observed series.

JEL classification: C22, C53, C82

Keywords: data revisions, state-space models, Kalman filter, Kalman smoother, trend-cycle decomposition
\end{abstract}

${ }^{*}$ Corresponding author: Jing Tian: School of Economics and Finance, Private Bag 85, University of Tasmania, Tasmania, 7001, Australia. Phone: +61-3-62262323. Email: jing.tian@utas.edu.au 


\section{Introduction}

The dynamics of measurement errors in data revisions can be cast in a statespace framework, as recently in Jacobs and van Norden (2011) (JvN henceforth). In providing this richer analysis, they employ restrictions on the covariance matrix of the state equation to identify revisions from previously unknown information (known in the data revision literature as 'news') from those due to a forecastable process ('noise').

Related parameter restrictions on the covariance matrix of the state equation are also employed in the Beveridge-Nelson (1981) trend-cycle decomposition literature (henceforth BN), see e.g. Morley (2002) and the single source of error approach of Anderson, Low and Snyder (2006). For a recent overview on parameter restrictions in state-space models see Jun et al. (forthcoming). Morley, Nelson and Zivot (2003) show that the difference between unobserved components models (UC) and Beveridge-Nelson (BN) decompositions stems from the restrictions on the correlation between innovations to trends and cycles.

Data revisions occur to an underlying series, until the final series value is reached. These final values are denoted as the 'truth' in JvN. They are interested in how the entry of previously unknown information and forecastable processes influences the evolution of this 'truth'. To identify the model, shocks to the previously unknown information and the 'truth' are assumed to be negatively correlated. The consequence of this is that the smoothed 
underlying 'truth' can become more volatile than the observed data. This is true even for stationary time series. Proietti (2006, p76) similarly noted that the trend may be more volatile than the observed data for BN trendcycle decompositions. This issue is also evident in the discussion of weighting patterns and smoothing in Koopman and Harvey (2003).

All computations in this paper are done in Oxmetrics 6.20, using the SsfPack libraries.

\section{The JvN model in the case of one release}

For simplicity we confine our attention to the case where we observe an original data release for a variable $y_{t}$, without a subsequent revision. The only source of measurement error is the new information. Then, the measurement equation for the observed variable becomes

$$
y_{t}=\tilde{y}_{t}+\nu_{t}=\operatorname{Truth}_{t}+\text { New Information } \text { I }_{\text {. }}
$$

Assuming an $\mathrm{AR}(1)$ process for the truth, the state equation becomes

$$
\left[\begin{array}{l}
\tilde{y}_{t+1} \\
\nu_{t+1}
\end{array}\right]=\left[\begin{array}{ll}
\rho & 0 \\
0 & 0
\end{array}\right]\left[\begin{array}{l}
\tilde{y}_{t} \\
\nu_{t}
\end{array}\right]+\left[\begin{array}{cc}
\sigma_{e} & \sigma_{\nu} \\
0 & -\sigma_{\nu}
\end{array}\right]\left[\begin{array}{l}
\eta_{e t} \\
\eta_{\nu t}
\end{array}\right],
$$


where $\boldsymbol{\eta}_{t} \sim N\left(0, \boldsymbol{I}_{2}\right)$. Note that

$$
\left[\begin{array}{cc}
\sigma_{e} & \sigma_{\nu} \\
0 & -\sigma_{\nu}
\end{array}\right]\left[\begin{array}{cc}
\sigma_{e} & \sigma_{\nu} \\
0 & -\sigma_{\nu}
\end{array}\right]^{\prime}=\left[\begin{array}{cc}
\sigma_{e}^{2}+\sigma_{\nu}^{2} & -\sigma_{\nu}^{2} \\
-\sigma_{\nu}^{2} & \sigma_{\nu}^{2}
\end{array}\right]=\sigma_{\nu}^{2}\left[\begin{array}{cc}
\frac{\sigma_{e}^{2}}{\sigma_{\nu}^{2}}+1 & -1 \\
-1 & 1
\end{array}\right]
$$

so the truth and new information shocks (given by $\eta_{e t}$ and $\eta_{\nu t}$ ) are negatively correlated, and the ratio $\frac{\sigma_{e}^{2}}{\sigma_{\nu}^{2}}$ plays an important role. If the ratio becomes large shocks to the truth dominate; if it becomes small, the covariance matrix becomes $\sigma_{\nu}^{2}\left[\begin{array}{cc}1 & -1 \\ -1 & 1\end{array}\right]$. This is precisely the covariance matrix of the state space representation of the Beveridge-Nelson decomposition; Morley, Nelson and Zivot (2003).

\section{$3 \quad$ Filtering and smoothing}

Figure 1 shows the smoothed and filtered truth together with the standardized simulated series from the model of Section 2 for $\left(\rho, \sigma_{e}, \sigma_{\nu}\right)=(0.25,0.5,0.5)$. We observe that the filtered truth is exactly the same as the simulated series, whereas the smoothed truth is very close to the observed series.

[Figure 1 about here.]

In Figure 2 we assume that disturbance of the new information is ten times larger than the disturbance of the truth $\left(\rho, \sigma_{e}, \sigma_{\nu}=0.25,0.5,2.5\right)$. The filtered truth is still exactly the same as the simulated series, but now the smoothed truth is much more volatile than the simulated series. 
[Figure 2 about here.]

The negative correlation between shocks to the truth and new information via data revisions implies that the volatility of the smoothed series is higher than the volatility of the simulated series. The variability of the smoothed series is increased when future measurement errors (which in this case pertain to new information) are negatively correlated with the truth disturbances.

Figure 3 shows the sensitivity of the variances of the smoothed truth and the filtered truth as the ratio $\frac{\sigma_{e}^{2}}{\sigma_{\nu}^{2}}$ varies. We let the size of both shocks vary from 0.05 to 5 , and hence the ratio $\frac{\sigma_{e}^{2}}{\sigma_{\nu}^{2}}$ ranges from $1: 10000$ to $10000: 1$. The top panel shows that when the shock to new information is much larger than the shock to truth, the smoothed truth is more volatile and the variance dramatically increases with the shock to new information. However, changes in the variance of the filtered truth are barely visible in the bottom panel.

[Figure 3 about here.]

The estimation results reported in $\mathrm{JvN}$ are based on data with four revisions. In all cases where new information shocks enter the state equation for the truth in the JvN data revision frameworks, the correlation between truth and new information shocks is negative. In addition, JvN find that shocks to new information are at least five times as large as those to alternative sources of shocks to the measurement error. Consequently, smoothed output growth is much more volatile than observed output growth. The existence of new information in the revision process of output growth suggests that 
statistical agencies act to smooth the 'noisy' true output growth series. It also sheds new light on the data reconciliation debate initiated by Stone, Champernowne and Meade (1942) on the choice of the better estimate of the growth rate of "true" output. For a recent contribution on the US see Fixler, Greenaway-McGrevy and Grimm (2011).

\section{Conclusion}

The JvN data revision model is related to trend-cycle decompositions in a way made obvious by the state space representation. Identification is achieved through restrictions on the variance-covariance matrix of the state equation, where the disturbances of the unobserved components are negatively correlated. This can result in the proposed 'truth' underlying the observed variable being more volatile than the observed data series.

These observations also hold when there are multiple revisions to a data series. The volatile nature of many real time data revisions does not therefor imply these data are non-informative, nor do our results support the tempting use of filtered data in place of such series. Future research will establish whether these properties apply to further economic series beyond the output data investigated in JvN. 


\section{References}

Anderson, Heather, Chian Nam Low, and Ralph Snyder (2006), "Single source of error state space approach to the Beveridge-Nelson decompoistion", Economics Letters, 91, 104-109.

Beveridge, Stephen and Charles R. Nelson (1981), "A new approach to decomposition of economic time series into permanent and ransitory components with particular attention to measurement of the 'business cycle"', Journal of Monetary Economics, 7, 151-174.

Fixler, Dennis J., Ryan Greenaway-MGrevy, and Bruce T. Grimm (2011), "Revisions to GDP, GDI, and their major components", Survey of Current Business, 91, 9-31.

Jacobs, Jan P.A.M and Simon van Norden (2011), "Modeling data revisions: Measurement error and dynamics of "true" values", Journal of Econometrics, 161, 101-109.

Jun, Duk Bin, Sungho Park Dng Soo Kim, and Myoung Hwan Park (forthcoming), "Parameter space restrictions in state space models", Journal of Forecasting.

Koopman, Siem Jan and Andrew Harvey (2003), "Computing observation weights for signal extraction and filtering", Journal of Economic Dynamics and Control, 27, 1317-1333. 
Morley, James C. (2002), "A state-space approach to calculating the BeveridgeNelson decomposition", Economics Letters, 75, 123-127.

Morley, James C., Charles R. Nelson, and Eric Zivot (2003), "Why are the Beveridge-Nelson and unobserved-components decompositions of GDP so different?", The Review of Economics and Statistics, 85, 235-243.

Proietti, Tomasso (2006), "Trend-cycle decompositions with correlated components", Econometric Reviews, 25, 61-84.

Stone, Richard, D. G. Champernowne, and J. E. Meade (1942), "The precision of national income estimates", Review of Economic Studies, 9, 111125. 
Figure 1: Smoothed and filtered truth and simulated series, $\left(\rho, \sigma_{e}, \sigma_{\nu}\right)=$ $(0.25,0.5,0.5)$
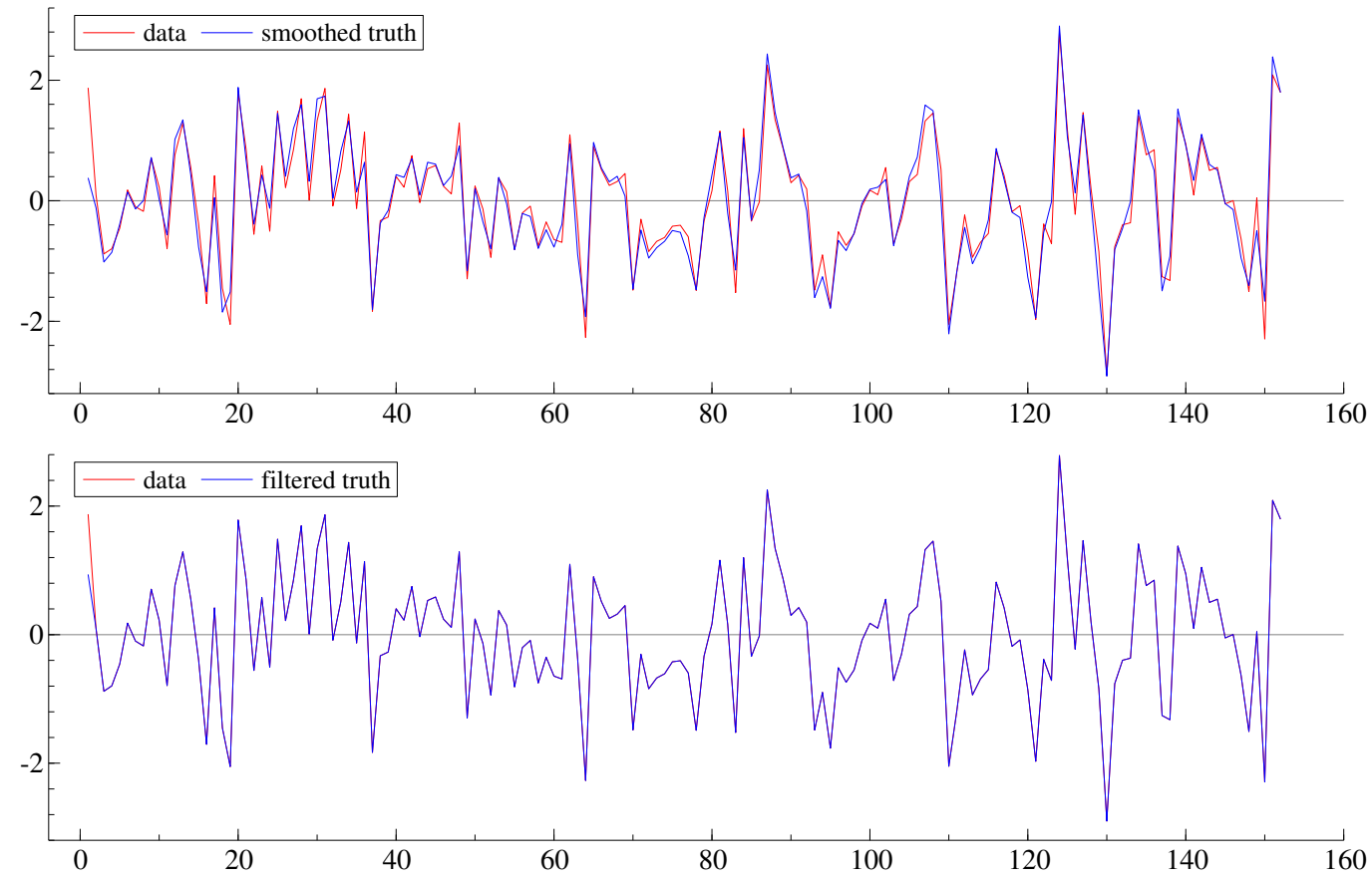
Figure 2: Smoothed and filtered truth and simulated series, $\left(\rho, \sigma_{e}, \sigma_{\nu}\right)=$ $(0.25,0.5,2.5)$
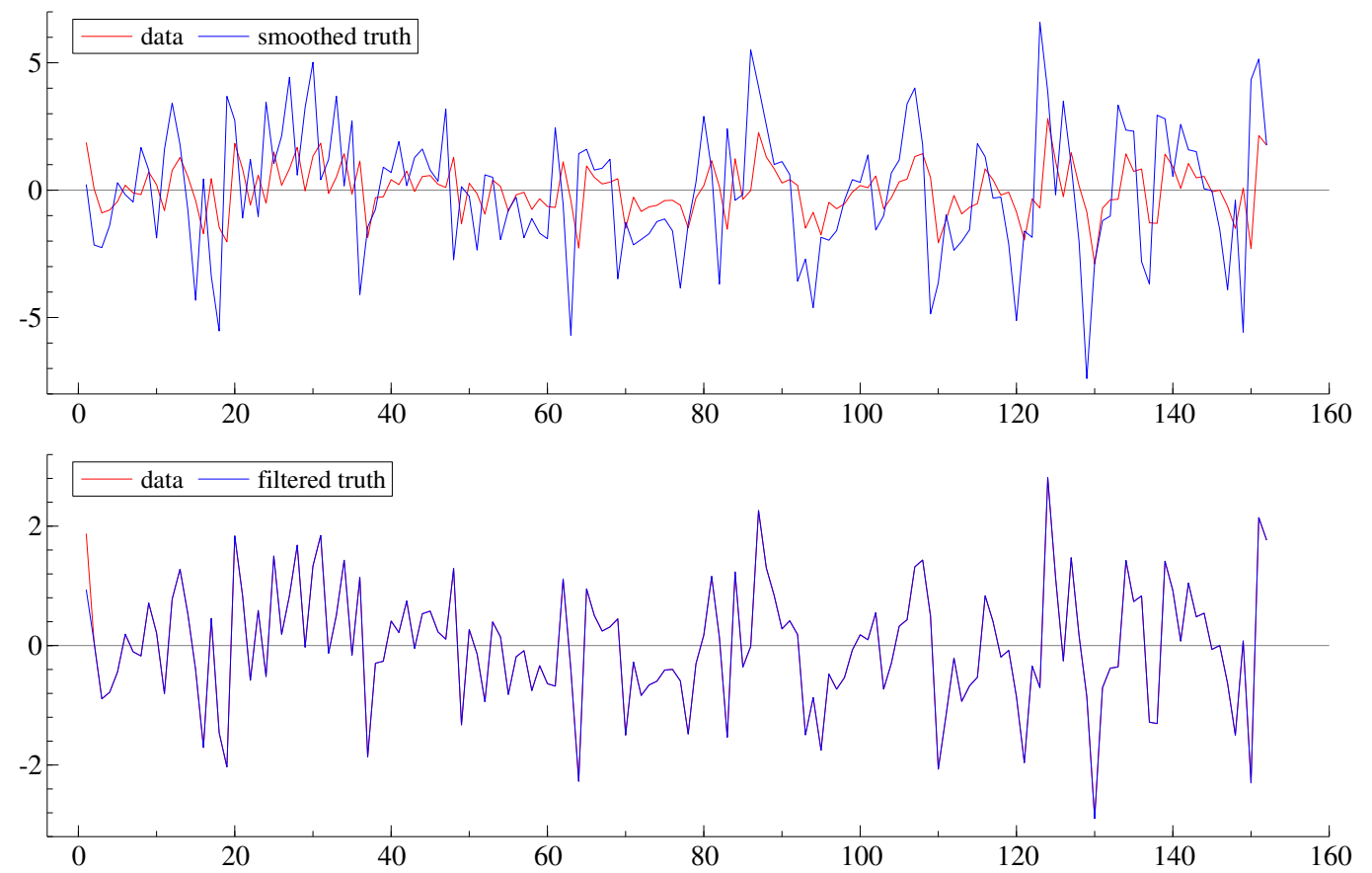
Figure 3: Sensitivity of smoothed and filtered truth and simulated series, to $\frac{\sigma_{e}^{2}}{\sigma_{\nu}^{2}}$
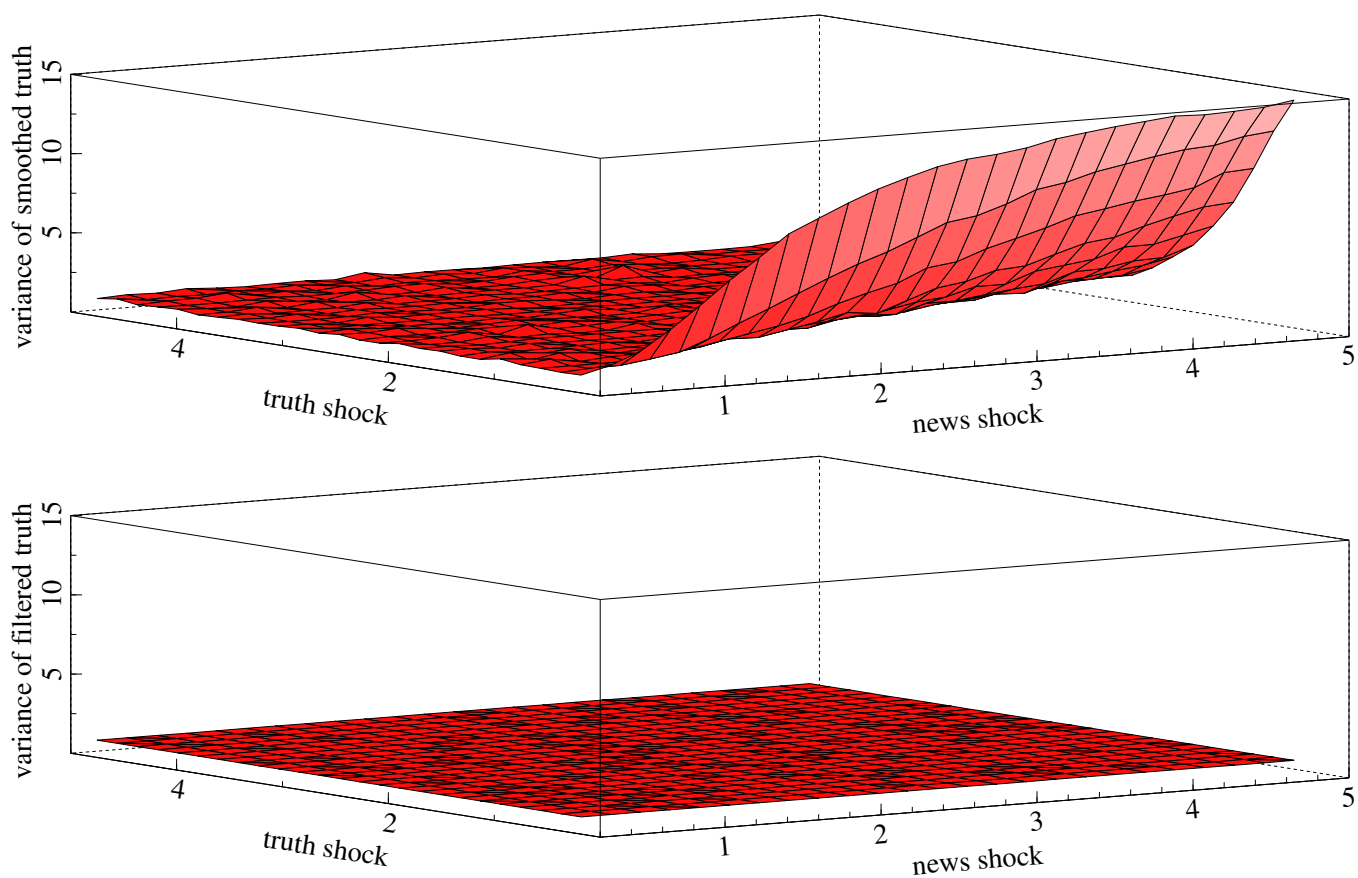


\section{School of Economics and Finance Discussion Papers}

2012-01 On the Correspondence Between Data Revision and Trend-Cycle Decomposition, Mardi Dungey, Jan PAM Jacobs and Jian Tian

2011-06 Systematic and Liquidity Risk in Subprime-Mortgage Backed Securities, Mardi Dungey, Gerald P. Dwyer and Thomas Flavin A SVECM Model of the UK Economy and The Term Premium, Mardi Dungey and M. Tugrul Vehbi

Do Contact Matter in the Process of Getting a Job in Cameroon? Firmin Doko Tchatoka and Urbain Thierry Yogo

2011-03 Subset Hypotheses Testing and Instrument Exclusion in the Linear IV Regression, Firmin Doko Tchatoka

2011-02 First home Buyers’ Support Schemes in Australia - Results Spreadsheet, Mardi Dungey, Graeme Wells and Sam Thompson

2011-01 First home Buyers’ Support Schemes in Australia, Mardi Dungey, Graeme Wells and Sam Thompson

2010-12 Financial Crises in Asia: Concordance by Asset Market or Country?, Mardi Dungey, Jan P.A.M. Jacobs and Lestano

2010-11 Innovation Contracts with Leakage Through Licensing, Shane B. Evans

2010-10 Franchise Contracts with Ex Post Limited Liability, Shane B. Evans

2010-09 Menus of Linear Contracts in Procurement with Type-Dependent Reservation Utility, Shane B. Evans

2010-08 Decomposing the Price Effects on the Cost of Living for Australian Households, Paul Blacklow

2010-07 Modelling the Time Between Trades in the After-Hours Electronic Equity Futures Market, Mardi Dungey, Nagaratnam Jeyasreedharan and Tuo Li

2010-06 Cojumping: Evidence from the US Treasury Bond and Futures Markets, Mardi Dungey and Lyudmyla Hvozdyk

2010-05 Assessing the Impact of Worker Compensation Premiums on Employment in Tasmania, Paul Blacklow

2010-04 Non-Linear Pricing with Homogeneous Customers and Limited Unbundling, Hugh Sibly

2010-03 Detecting Contagion with Correlation: Volatility and Timing Matter, Mardi Dungey and Abdullah Yalama

Copies of the above mentioned papers and a list of previous years' papers are available from our home site at http://www.utas.edu.au/ecofin 